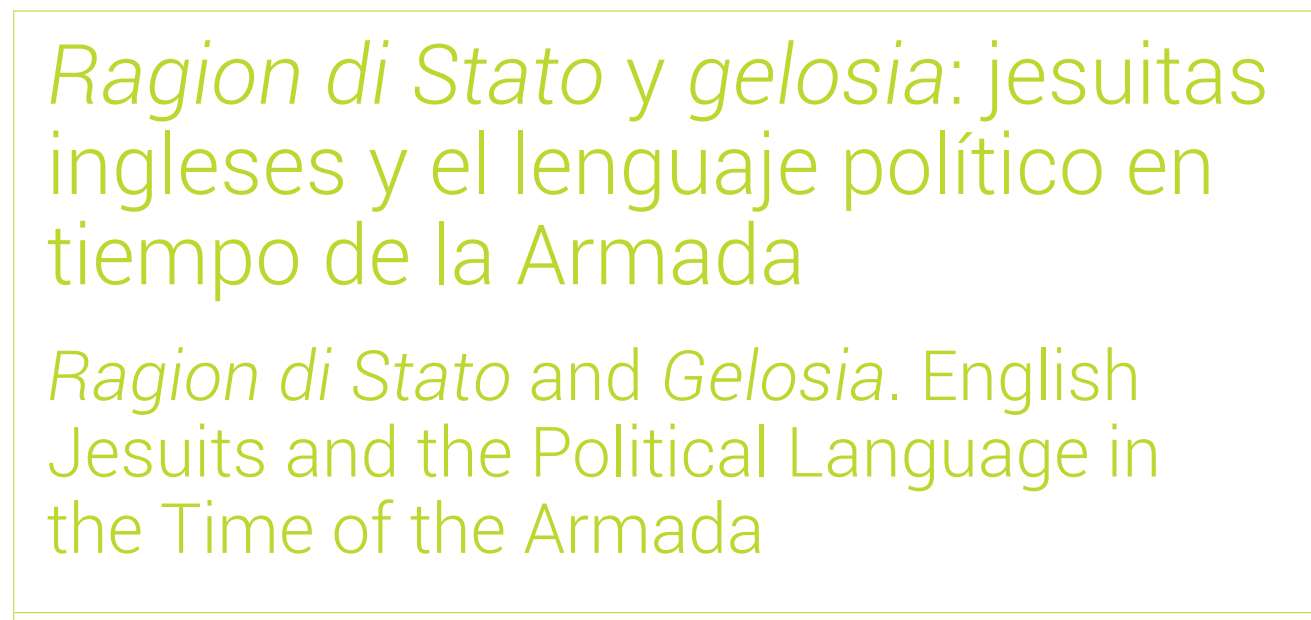

\title{
Marcella Miranda
}

Universidade de São Paulo

BRASIL

marcellagmiranda@gmail.com

[Hipogrifo, (issn: 2328-1308), 7.2, 2019, pp. 473-484]

Recibido: 11-06-2018 / Aceptado: 13-08-2018

DOI: http://dx.doi.org/10.13035/H.2019.07.02.37

Resumen. El objetivo de este trabajo es presentar el marco general de la circulación de los jesuitas ingleses en Europa, en el contexto de la persecución a los católicos en Inglaterra y a los padres de la Compañía de Jesús. La investigación pone el foco en los jesuitas que se aliaron con Felipe II, creando el partido católico liderado por William Allen, Robert Persons y Joseph Creswell. Durante más de veinte años, estos jesuitas desarrollaron una intensa labor física, desplazándose por el continente europeo, fundando colegios ingleses y buscando recursos para la empresa de Inglaterra. Sin embargo, la principal herramienta que emplearon fue la pluma. En 1588 y otra vez en 1596, ellos fueron los responsables de plantear y justificar la opción política de la candidatura de la infanta Isabel Clara al trono de Inglaterra. Al hacer uso de un concepto novedoso en la época, el de la razón de Estado, los jesuitas fraguaron el lenguaje político de la Monarquía Hispánica como anclaje del equilibrio de la república cristiana. Antes que Botero publicase la obra Della ragion di Stato, ellos formularon el concepto de razón de Estado que, según su semántica política, significaba básicamente la justa defensa de los intereses dinásticos de los príncipes cristianos y no, como se atribuye a Maquiavelo, el puro apetito de poder.

Palabras clave. Compañía de Jesús; Monarquía Hispánica; Razón de Estado

1. Estudiante de doctorado en Historia Social de la Universidad de São Paulo-USP. Becaria FAPESP (São Paulo Research Foundation). 
Abstract. This work aims to present the general framework of the circulation of Elizabethan Jesuits in Europe, in the context of the increasing persecution against the Catholics and the fathers of the Society of Jesus in England. This investigation focuses on the Jesuits that joined up Philip II of Spain, by founding the Catholic party led by William Allen, Robert Persons and Joseph Creswell. During more than twenty years, those Jesuits made an intense effort, moving around Europe, to establish English colleges and raise funds for the England's enterprise. However, the main weapon they employed has been the feather. In 1588 and once again in 1596, they were responsible for proposing and justifying the political claim of the infanta Isabel Clara to the English Crown. By using a new concept at that time, the Reason of State, the Jesuits shaped the political language of the Spanish Monarchy as anchorage of Republica Cristiana's balance of power. Even before the publication of the book Della ragion di Stato, by Giovanni Botero, the Jesuits elaborated a concept of Reason of State that, according to its political semantics, did not merely mean the pure appetite for power, as usually attributed to Machiavelli, but a fair defense of dynastic interests of the Cristian princes.

Keywords. Society of Jesus; Spanish Monarchy; Reason of State.

\section{INTRODUCCIÓN²}

En la primera mitad del siglo XVI, la aparición de la Compañía de Jesús ha sido el resultado del proyecto de renovación espiritual liderado por Ignacio de Loyola. Así lo manifestaba este a través de los puntos desarrollados en los Ejercicios Espirituales, un manual de conducta para el examen de consciencia de los individuos, basado en la meditación, contemplación y oración. Tras la creación de la orden en 1540, los jesuitas fueron tomando para sí la tarea de vigorizar y expandir el catolicismo, por medio de la fundación de colegios y misiones en las cuatro partes del mundo. El contexto de la búsqueda de reformulación espiritual, combinando las experiencias individuales orientadas por los Ejercicios Espirituales con la organización institucional promovida por las Constituciones, ha sido denominado como «momento teológico jesuítico» ${ }^{3}$. Es decir, se plantean las bases de un modelo teológico que presupone la conciliación entre la doctrina escolástica con las aportaciones del ciceronianismo italiano. Para este fin, se mantuvieron los estudios de retórica heredados de los Studia Humanitatis, ajustados al propósito de la exhortación cristiana. En ese sentido, la predicación, la confesión y la educación se convirtieron en la tríada de la acción jesuítica en el mundo ${ }^{4}$. Según Joseph Creswell, los estudios de los alumnos en los seminarios quedaban sostenidos básicamente por dos pilares:

Procuramos que tengan buenos libros, que les desengañen, y personas doctas, que con la predicación, conversación y ejemplo de su vida autoricen la verdad

2. Las abreviaturas utilizadas en este artículo son las siguientes: AGS (Archivo General de Simancas), BNE (Biblioteca Nacional de España), BRP (Biblioteca Real del Palacio).

3. Iñurritegui Rodríguez, 1998, pp. 78-86.

4. «El Padre Joseph Cresuelo. En razón de socorrer los Seminarios de Ingleses en Flandes», BRP, II, 2225, doc. 23 , fol. 72 r. 
y fomenten el espíritu de Dios con sacramentos. Pues por estos mismos medios se han convertido los demás reinos ${ }^{5}$.

En esa época, la orden jesuítica no tuvo permiso para instalarse en Inglaterra. Durante el reinado de María Tudor (1553-1558), las peticiones de Ignacio de Loyola para autorizar la entrada de la orden en Inglaterra fueron denegadas. El Gobierno siguiente, de Isabel I (1558-1603), promulgó el settlement religioso estableciendo el culto protestante. El Act of Uniformity promovió la unificación del culto anglicano a partir de algunos cambios del Book of Common Prayer de la época de Eduardo VI. La ley volvió el ritual religioso a una manera más tradicional, además de establecer una multa a las personas que no fuesen al culto una vez a la semana. El giro conciliador de la reina hizo mantener ciertas prácticas tradicionales del rito católico ${ }^{6}$. La intensificación de la persecución a los católicos empezó tras la rebelión norteña (1569) y cuando el papa Pío V excomulgó a Isabel I en 1570. El resultado fue que muchos católicos, particularmente los religiosos, tuvieron que exiliarse para seguir practicando su religión.

En 1580, el general de la orden Everardo Mercuriano aprobó la primera misión jesuítica en Inglaterra, bajo la dirección de Robert Persons. Las andanzas de dos clérigos católicos pronto generaron sospechas y terminó con la tentativa de arresto de los jesuitas. El padre Edmund Campion, compañero de Persons, fue capturado y ejecutado por traición, mientras Persons huyó para el continente. Así, los intentos de enviar padres de la Compañía tras 1580 provocaron la dura reacción del Gobierno contra los recusantes ${ }^{7}$. En octubre de 1591, se divulgó una proclamación contra los jesuitas ${ }^{8}$, acusándoles de traicionar a la nación inglesa al conspirar junto con el papa y Felipe $I^{9}$. Las acusaciones terminaron generando una verdadera disputatio entre el Gobierno inglés y el grupo católico exiliado ${ }^{10}$.

\section{LA FORMACIÓN DEL PARTIDO}

William Allen (1532-1594) era un joven estudiante de Artes en la Universidad de Oxford cuando Isabel I ascendió al poder. Tras rehusar obediencia a la reina, huyó para Louvain, donde se unió al grupo católico exiliado cercano a Nicholas Sanders ${ }^{11}$. En 1568, fundó el colegio inglés en Douai que luego tuvo que trasladarse

5. «El Padre Joseph Cresuelo», fol. 72r.

6. McCoog, 1996, p. 43.

7. El término recusante se atribuía a los católicos que se negaban a frecuentar el culto anglicano, situación que les imponía el pago de una multa: «Soon the activity - recusancy- signified catholicism itself: by refusing church attendence a man distinguished himself clearly from Protestants, and shoed himself and the world what he was» (Holmes, 1982, p. 83).

8. Para Robert Persons, el documento había sido escrito por William Cecil. Ver Houliston, 2001, p. 384.

9. Tanner, 1951, p. 154.

10. Para una síntesis, Lake, 2016 y Domínguez, 2011.

11. Sanders, exprofesor de Cánones en Oxford, se exilió en Lovaina. Es autor de la obra De Visibili Monarchia Ecclesiae (1571), una de las principales refutaciones católicas a los protestantes. 
hacia Rheims por la irrupción de la guerra contra Felipe ${ }^{12}$. Poco después, Allen obtuvo la protección del rey de España y pasó a recibir limosnas para su seminario. Desde Rheims, él estrechó el contacto con Bernardino de Mendoza ${ }^{13}$ y Juan Bautista de Tassis, embajadores de España en Inglaterra y en Francia, respectivamente. En la relación de gastos hecha por Tassis y enviada a los contadores del rey, figura el pago a Allen en la categoría de propina a las personas particulares ${ }^{14}$.

Robert Persons (1546-1610) fue el brazo derecho de William Allen hasta su muerte en 1594. Estudiante y tutor en Balliol College, Oxford, se vio obligado a retirarse por problemas religiosos y personales. De allí se trasladó a Roma para hacerse jesuita, y luego fue nombrado rector del colegio inglés de la ciudad. Persons era un verdadero nómada, trasladándose entre Roma, Francia y España para ganar apoyos en la empresa de Inglaterra. Tras la desgracia de la Armada, viaja a España, donde fundó los colegios de Valladolid y Sevilla. Persons tomó bajo su protección a un joven que conoció durante su misión en Inglaterra, Joseph Creswell.

Creswell (1556-1623) pertenecía a una familia modesta de recusantes en Londres. Cuando su madre murió, él se exilió en Francia y luego fue a Roma para iniciar sus estudios en el colegio inglés ${ }^{15}$. Algunos años después, se unió a la Compañía de Jesús y, después de la Armada en 1588, fue nombrado por Persons rector del colegio inglés de Roma, donde sirvió hasta ser convocado a España, actuando allí como vice-rector de los colegios de la orden.

El aumento de la persecución a los católicos y la recusa disimulada de Jacobo VI de Escocia a abandonar la fe protestante llevaron a la formación del partido inglés liderado por Allen, cuyo objetivo era defender la alianza con España como eje principal de toda la labor para la restauración del catolicismo en Inglaterra. Según un memorial escrito por Creswell, «la principal persona de todos los ingleses que están desterrados es el Cardinal Alano, y con él están unidos todos los demás católicos, dentro y fuera del reino» ${ }^{16}$. Sin embargo, el vínculo de esos jesuitas con la Monarquía Hispánica fue motivo de sospechas por parte de otros católicos y también del papa. El grupo de los exiliados acabó por dividirse en dos, el pro-español, de Allen, y el pro-escocés, de Charles Paget y Thomas Morgan ${ }^{17}$.

\footnotetext{
12. Persons, Elizabethae Angliae reginae...

13. Según Persons, Mendoza era el más fervoroso representante del rey para amparar a los católicos ingleses y tenía la total confianza de los jesuitas. Ver Hicks, 1942, pp. 70-71.

14. Sumario de la cuenta que ahora se envía a España de gastos hechos desde primero de mayo de ochenta y dos años hasta fin de hebrero de ochenta y tres años, que son diez meses, AGS, Est., K, Leg. 1561, fol. 35 .

15. Loomie, 1963, p. 182.

16. Información de las cosas y personas de Inglatierra en cuanto al gobierno de Flandes..., Tomo I, BNE, ms. 8.695, fol. $841 \mathrm{v}$.

17. «La causa por que se apartaron de los demás al principio fue porque vieron que el Cardinal Alano, el Padre Personio, el señor Francisco Englefild y Hugo Oen, que trataban los negocios públicos de ella, procuraron animarse totalmente a España [...] no pudieron estos dos llevar con paciencia que se dependiese de España, y así procuraron primeramente de desviar a la dicha reina de Escocia a ponerla en duda y sospecha en todo lo que se trataba por vía de España» (Información de las cosas y personas de Inglatierra, fol. 841v).
} 
En los años 1580, había un elemento que dificultaba aún más las negociaciones de los jesuitas ingleses: la retención de María Estuardo, heredera del trono inglés, en la prisión en Inglaterra. La situación forzaba a que las negociaciones para la empresa de Inglaterra incluyesen la cuestión de Escocia, por los vínculos dinásticos que tenían las dos coronas, algo que no animaba al partido de Allen ${ }^{18}$. Este grupo creía que la protección de España era la única solución, mientras el grupo de Sir Charles Paget conspiraba para liberar a María Estuardo y hacerla reina de Inglaterra y Escocia.

Mientras trabajaban en las sombras para recuperar las almas de los fieles, los religiosos se enfrentaban al dilema de esperar por la restauración del catolicismo tras la muerte de la reina o de inmiscuirse en las estratagemas para deponer a Isabel I ${ }^{19}$. Por el fracaso de la primera misión inglesa, Persons llegó a la conclusión de que la reducción de Inglaterra no podría conseguirse sin la fuerza de las armas ${ }^{20}$. Así, Allen y Persons ampliaron sus trabajos para apoyar la intervención militar. Tras derrota de los partidarios de don Antonio en la Isla Tercera, en 1583, Felipe II ya podría desviarse de Portugal para organizar la empresa de Inglaterra. Con los preparativos de la Invencible Armada a toda máquina, la ejecución de María Estuardo, en marzo de 1587, abrió el camino para proponer los derechos de la infanta Isabel Clara a la Corona de Inglaterra.

\section{EL EMPLEO DE LA PLUMA}

Una de las principales estrategias que adoptaron los jesuitas fue la escritura. Para tal fin, dedicaron un esfuerzo monumental para publicar y difundir varios tipos de textos, como libros, librillos, memoriales y panfletos, impresos o manuscritos, para combatir los argumentos de los protestantes y amparar la resistencia de los católicos. Más allá, se ocuparon de mantener la prensa en los colegios o cercanías, encargándose de publicar diversos tipos de textos, desde los devocionales hasta aquellos de naturaleza política. En la ocasión de la Armada, los dichos textos buscaron justificar la invasión de Inglaterra y legitimar los derechos de la infanta Isabel Clara.

La labor inicial para ganar apoyos a la invasión se tradujo en un intenso intercambio de correspondencia y encuentros de los jesuitas con el embajador de España en Roma, el conde de Olivares. La facción de Allen fue el puente entre Felipe II y el papa Gregorio XIII en las negociaciones sobre la Armada; de hecho, los jesuitas escribieron una serie de instrucciones a Felipe II sobre cómo argumentar con el papa en relación a los motivos para hacer la empresa. Si una cosa estaba clara para Felipe II era que el punto neurálgico del argumento no radicaba tanto en materia de religión, sino en materia de Estado. Por esa misma razón, el Rey Católico seguía exhortando al conde de Olivares a reforzar ante el papa la santidad de la empresa:

18. «Juan Bautista de Tassis a Su Majestad. De París, a 27 de mayo 1584», AGS, Est., K, Leg. 1563, fol. 17.

19. Holmes, 1982

20. McCoog, 2001, pp. 140-175. 
Que por Su Santidad no se embarace con la sombra que podría dar a otros príncipes del juntar y pegar más reinos a los de Su Majestad le podrá decir como no es su intento unir este con los otros, sino que, si Dios se sirviera de poner esto en tal estado, se contentará de disponer de ello en favor de la señora infanta para que, casándose y residiendo en el mismo reino, tanto más presto se restaure en él nuestra santa fe católica con la presencia de sus Reyes Católicos y celosos como con ayuda de Dios lo serán de estenderla ${ }^{21}$.

El tema de la conservación y expansión de los Estados ganaba más y más fuerza en la literatura política de la época22. Un año después, saldría a la luz la obra de Giovanni Botero, Della ragion di Stato, la primera que teorizó el concepto de razón de Estado. En la carta de Felipe II, el paradigma conservativo se insertase más propiamente dentro de la esfera providencialista, siendo expresión de la voluntad de Dios, y no tan abiertamente de la razón de Estado, o sea, expresión del interés particular o dinástico en la manutención de su propio poder ${ }^{23}$. Si las cosas de Inglaterra habían llegado a tan mal punto, era por la voluntad de Dios, así como lo sería la conquista y manutención de Inglaterra por la Monarquía Hispánica. La simbiosis autorizaba, por tanto, la anexión de Inglaterra por el Rey Católico.

Sin embargo, el ámbito de la práctica política era algo más complicado, obstáculo que los clamores providencialistas del Rey Católico no podrían fácilmente allanar. En ese contexto, Allen y Persons asumieron la tarea de solucionar dos problemas: aclarar los derechos de la infanta al trono de Inglaterra y convencer al papa y a todo el orbe cristiano de que la empresa se hacía por motivos justos, procurando neutralizar las acusaciones que se pudieran lanzar contra Felipe II. En febrero y marzo de 1587, aún antes de que se conociera la ejecución de María Estuardo, Robert Persons tuvo una serie de encuentros con Olivares, en los que se reflexionó sobre la Armada y la mejor manera de proponer la cuestión de la sucesión a la curia romana. La materia era bastante sensible, como vemos en el siguiente memorial de Persons, Consideratione per le quale para che in nisun modo convenga che il interese particolare de Sua Maiestà a la successione de Inglaterra se proponga al Papa avanti l'empresa:

Le dani e impedimenti che ne potrebono seguire: Et l'istesso Papa e diversi Cardinali intrar potrebono forsi invari pensieri discorsi et sospeti por ragione di stato de actioni di Sua Maestà intorno aquesta impresa ne concorrebbe per aventura Sua Santità tanto liberalmente o con favori o con denari cuando se le direbbe d'alcuno che Sua Maestà in questa impresa tratta principalmente del suo interesse particolare ${ }^{24}$.

¿Qué pasaría si, a los ojos del papa y del mundo, los intereses particulares involucrados en la operación llamasen más la atención que el verdadero celo de la religión? La sospecha de la razón de Estado se confirmaría en caso de que fuese

21. «Al conde de Olivares, puntos para responderle», AGS, Est., Leg. 949, fol. 24.

22. Gil Pujol, 2016.

23. Fernández Albaladejo, 2005, p. 35.

24. «Entregada al conde de Olivares por Melino a 18 marzo 1587», AGS, Est., Leg. 949, fol. 25. 
desvelada la intención de incorporar el reino inglés a la Monarquía Hispánica, concediendo la soberanía del territorio a la infanta. El juntar y pegar otros reinos provocaría así una reacción negativa tanto de los príncipes católicos como protestantes, y eso no era algo baladí:

Le eresia de Inghilterra con questa sola voce de la pretensione di Spagna se agintarebbono grandemente primo facendo l'actioni di Sua M Sua Maestà daquesta impresa odiosa a tutti l'altri Principi tanto heretici come Cattolico como se Spagna volesse signorear tutta l'Europa. E cosi farebbono la causa loto piu favorebole dicendo che non fosse por religione ma per ragione di stato 25 .

El lenguaje de la razón de religión, aplicado a la esfera práctica, requería también el cuidado con la dimensión de la política. Si la Armada Invencible se justificase en nombre del ensalzamiento de la fe católica, no conseguiría tan fácilmente superar los inconvenientes negocios de la razón dinástica. En ese sentido, los jesuitas se aplicaron en la tarea de conceder a Felipe II la receta ideal para neutralizar la oposición de sus competidores. El argumento principal no radicaba en el providencialismo, sino en la razón de Estado. Su semántica era sencilla: al tratarse del juego de los intereses dinásticos de los príncipes, era propio al mundo de las cosas terrenales. Nada más natural, por lo tanto, que la celosía de la grandeza del Rey Católico recibiera como respuesta más eficaz la práctica mundana de la disimulación. Era necesario que se mantuviese en secreto los planes para la infanta:

Por la medesima causa l'altri Principe cristiani e Cattolico potrebono molto piu por ragione di stato entrare in gelosia della grandeza di Spaña particolarmente il Re di francia il quale con questa cagione e pretesto tirarebbe molti altri seco a disfaborir l'Impresa, il medesimo farebonno i Principe italiani [...] II Principi di Guisa e di la Casa di Lorena in Francia i quali facilmente indurrano a concurrir e gionar questa empresa al manco a proibir que Francia non impedisca, con questo sospetto si alienarebbeno come ancora molto piu tutti quelli di Scotia li quali in la empresa sarano di grandissima importanza e facilissimamen ${ }^{\text {te }}$ se potrano haver per noi si questa pretensione de Sua Maestà se tiene secreta ${ }^{26}$.

Los jesuitas lograron éxitos momentáneos: el papa por fin aprobó la empresa y elevó a William Allen al cardenalato; este sería responsable de la transición religiosa en Inglaterra tras la invasión, plenamente revestido con el manto rojo. Joseph Creswell fue entonces enviado a Bruselas como capellán del ejército de Flandes. Él había escrito un edicto a petición del duque de Parma, el gobernador de los Países Bajos, «que entonces se imprimió en lengua inglesa para declarar la piadosa intención de Vuestra Majestad y quedan algunos millares de copias depositadas en Dunquerque» ${ }^{27}$. Aunque el fracaso de la Armada se tradujo en un duro golpe para los católicos exiliados, no se apagó la llama de la esperanza. 
En los años postreros, los jesuitas ingleses seguían exhortando a Felipe II a planear otras empresas contra Inglaterra. Conforme la reina Isabel I envejecía y crecían los apoyos a Jacobo VI de Escocia, se hacía cada vez más urgente para la facción de Allen solventar el tema de la sucesión. La toma de conciencia de esa emergencia llevó al abandono del discurso relativamente moderado contra Isabel I para abrazar con todos los medios posibles la causa de la infanta. Tras la muerte del cardenal Allen, Persons se convirtió en líder del partido. Por eso, él va escribir varios textos devocionales y políticos, algunos publicados anónimamente. Por la cantidad y calidad de los textos, el historiador Peter Holmes le describía como «the most prolific and successful Elizabethan catholic writer» ${ }^{28}$.

En 1595, Robert Persons publicó en Amberes el libro A Conference about the Next Succession to the Crown of England bajo el pseudónimo de Robert Doleman ${ }^{29}$. El lenguaje político elaborado por los jesuitas iba, una vez más, a centrarse en dos puntos: neutralizar la acusación de la razón de Estado y desacreditar la primacía del derecho de sangre entre los competidores de la Corona de Inglaterra. Hemos visto que los jesuitas ya habían desarrollado el primer punto con ocasión de la Armada. Por tanto, era necesario poner énfasis en los discursos sobre los derechos sucesorios ${ }^{30}$.

La obra estaba compuesta por dos libros: el primero trataba sobre un discurso del letrado en derecho civil y canónigo sobre la teoría política y el segundo sobre la presentación, por el letrado del reino, de los principales competidores a la Corona de Inglaterra, entre ellos Felipe II y la infanta. En ese libro, Persons presentó su más profundo estudio y argumentación sobre la teoría política contractualista y su despliegue en el derecho sucesorio inglés. La recepción de la obra fue bastante polémica. Además de los enemigos evidentes, muchos católicos manifestaron recelos en cuanto al contenido ${ }^{31}$, en particular por la impronta radical del derecho de resistencia de los súbditos a un rey hereje ${ }^{32}$.

Tenemos motivos para pensar que Joseph Creswell se encargó de la traducción del original al latín 33 , y quizás también al español. Cada versión del libro presenta algunas modificaciones y capítulos distintos, dirigidos a las respectivas audiencias a que iban a someterse. El manuscrito español contiene un breve resumen del primer libro (más sencillo que la versión latina) y la traducción de los ochos primeros capítulos del segundo libro. Nos interesa subrayar el intento de Persons de promover un candidato católico a la vez que jerarquiza las condiciones ideales para el suce-

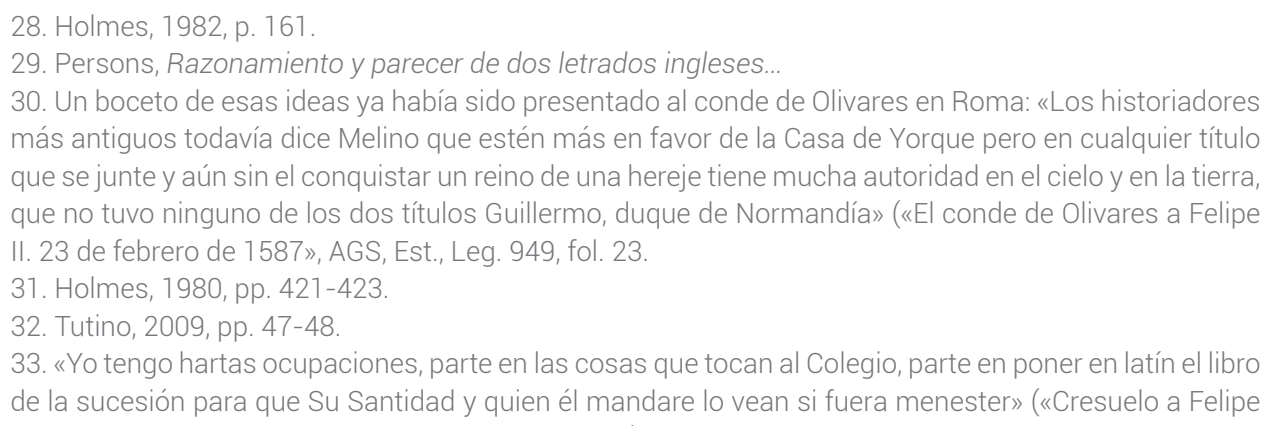


sor, cuya estrategia se basada en la sumisión del derecho de sangre a la condición primera del pacto político:

En la sucesión de un reino no se ha de mirar solamente la propincuedad de sangre y mayor parentesco, como falsamente pretende y afirma Bellay en favor de Vandoma ${ }^{34}$, sino también otras circunstancias y condiciones y sobre todas las religiones y culto divino, sin las cuales cosas no queda la república con obligación de admitir por su rey a príncipe ninguno, aunque por vía de conjunción de sangre le tocase la sucesión, pues el más alto y principal fin que las repúblicas tuvieron en escoger y autorizar cualquier género de magistrado y gobierno fue la conservación de la religión y culto divino, sin lo cual no puede el ánima llegar a su bienaventuranza ${ }^{35}$

Aunque el libro de la sucesión se propone presentar una visión imparcial de los derechos de cada uno de los candidatos a la Corona de Inglaterra, sabemos que en realidad preparaba el camino a la causa de la infanta ${ }^{36}$. Entre bastidores, los jesuitas seguían intentando persuadir a Felipe II para hacer la empresa, asegurándole la fidelidad de los católicos que permanecían en la isla. La tarea de poner en práctica los argumentos del libro estuvo a cargo de Joseph Creswell. Mientras traducía al latín la obra de Persons, Creswell había enviado el memorial sobre los derechos de la infanta a Felipe II. El papel, titulado Razones por las cuales los católicos de Inglaterra desean que la Señora Infanta de España se prefiera en la sucesión del reino a los demás pretensores, salió a la luz poco después de la toma de Cádiz por los ingleses. Era, tal vez, la última oportunidad para los exiliados.

Creswell resumió los puntos fundamentales que sostenían la pretensión de Isabel Clara:

Aunque la razón principal que mueve a los dichos católicos de mirar con tanto cuidado es por la sucesión del reino es la siguridad de la religión, la cual por ningún otro medio que al presente se ofrece les parece posible sino por este de la Señora Infanta: Todavía concurren también en esta misma persona tantas otras partes y circunstancias, cuantas en otra ninguna que se puede señalar, como: derecho y cercanía de sangre; la posibilidad para alcanzar su derecho, y para defenderlos después; las partes para gobernar a contento de todos, razón de Estado de toda la cristiandad, de los otros príncipes circunvecinos; la paz y unión del reino y seguridad y comodidad de los demás pretensores domésticos; la voluntad e inclinación de la república, y otras semejantes ${ }^{37}$.

Por supuesto, los elementos subrayados por el jesuita tenían que ver no solo con los derechos dinásticos, pues también consideraba un conjunto de factores puramente políticos. A la defensa de la religión católica le seguía una evaluación de la capacidad de la futura reina (y su padre) de sostener las riendas del poder y garantizar la concordia entre los súbditos, además de pacificar (y comprar) volun-

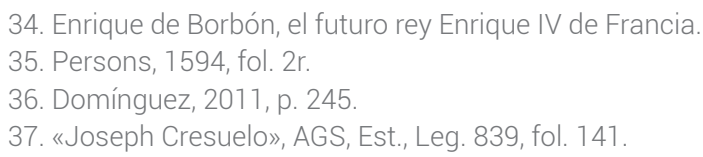


tades. En este punto, Creswell tenía claro que el derecho dinástico no debería ser el principal definidor del sucesor: «Y se ha de advertir que con mucho menos derecho de sucesión y con menores necesidades públicas se han puesto muchos Reyes en Inglaterra en otras ocasiones, los cuales todavía han salido los mejores que aquella Republica ha tenido»38. De ese modo, los jesuitas de Felipe II le ofrecían la razón para convencerle a hacer la empresa, preparándole al mismo tiempo un arsenal de argumentos con que refutar a sus opositores.

La paciencia de los padres de la Compañía fue contestada con la irresolución del monarca que, en esta época, se hallaba inmerso en las guerras en Francia y en los Países Bajos. Por eso mismo, era esencial poner énfasis en la idea de la paz como uno de los puntos favorables a la infanta:

En lo $5^{\circ}$, que es razón de Estado de toda la cristiandad de los príncipes circunvecinos, fácilmente se ve que ninguno de los demás pretensores podrá ser tan a propósito para dar satisfación a todos como esta señora. Primeramente, porque a la sede apostólica, ultra la seguridad que hemos dicho de las cosas de la religión, estará muy bien que Inglaterra sea reino por sí, y no se junte con otro, y que haya un rey católico hijo fiel desta Santa Iglesia para ayuda de toda la cristiandad, tan quebrada en aquellas grandes provincias septentrionales ${ }^{39}$.

En la ocasión de la primera Armada, el «juntar y pegar» otros reinos estaría justificado para Felipe II por los diseños de la providencia. Aun así, a los jesuitas les pareció más prudente ocultar los planes del papa hasta que la Armada zarpase. En 1596, estamos otra vez ante el paradigma conservativo, manipulado de tal modo que la cesión de la soberanía del reino anglicano a la señora infanta no se tradujese necesariamente en una ampliación de los territorios de la Monarquía Hispánica. Todo lo contrario, Inglaterra sería mantenida como reino aparte, favoreciendo el equilibrio entre las principales naciones europeas. La razón de Estado no era entendida como pura ambición de príncipes, sino como el elemento neutral que genera el punto de estabilidad entre los intereses particulares de los Estados. Con esta justificación, Creswell podría aprovecharse de la antigua enemistad entre Francia e Inglaterra:

Y si miramos la razón de Estado de los demás príncipes comarcanos, síguese lo mismo, porque al rey de Francia estará mucho mejor que el reino de Inglaterra sea de la Señora Infanta, y por esta vía reino aparte, que no sea del rey de Escocia, que es el primero de los pretensores domésticos, el cual si tuviese los tres reinos juntos de Inglaterra, Escocia e Irlanda sería muy poderoso para pretender luego la acción que los reyes de Inglaterra pretenden a las coronas de Francia ${ }^{40}$. 


\section{CONCLUSIÓN}

La segunda Armada de Felipe II también fue un desastre. La guerra con Francia terminó en la firma de la Paz de Vervins (1598). Entre 1600-1603, Persons y Creswell continuaron enviando sucesivos memoriales y cartas a Felipe III sobre la materia de la sucesión. Instado por los escritos de los jesuitas, el Consejo de Estado recomendó al joven rey a no perder la ocasión para actuar e imponer un candidato apetecible a Madrid. Sin embargo, el viento ya soplaba para favorecer un acuerdo de paz. La cesión de los Países Bajos españoles al archiduque Alberto e Isabel Clara también complicaba los planes de los jesuitas para la infanta. Por eso mismo, Felipe III no tomó en serio los clamores de los padres. Con la firma del Tratado de Londres (1604) con Jacobo VI, a los recusantes solo les quedaban dos opciones: someterse al nuevo Gobierno o exiliarse y clamar por la tolerancia religiosa. La invasión por vía de armas ya no fue más una opción.

\section{BibLIOgRAFÍA}

Domínguez, Freddy, «We must Fight with Papers and Pens»: Spanish Elizabethan's Polemics. 1585-1598, Dissertation, Princeton, Princeton University, 2011.

Fernández Albaladejo, Pablo, «Entre la razón católica y la razón de Estado. Senderos de la raison politique en la Monarquía de España», en La paix des Pyrénées (1659) ou le triomphe de la raison politique, ed. Lucien Bély, Bertrand Haan y Stéphane Jettot, París, Les classiques Garnier, 2005, pp. 37-49.

Gil Pujol, Xavier, La fábrica de la monarquía. Traza y conservación de la monarquía de España de los Reyes Católicos y los Austrias, Madrid, Real Academia de Historia, 2016.

Hicks, Leo, S.J., Letters and Memorials of Father Robert Persons, S.J., vol. 1, Londres, Catholic Record Society, 1942.

Holmes, Peter, «The Autorship and Early Reception of a Conference about the Next Succession to the Crown of England», The Historical Journal, 23.2, 1980, pp. 415-429.

Holmes, Peter, Resistance and Compromise. The Political Thought of the Elizabethan Catholics, Cambridge, Cambridge University Press, 1982.

Houliston, Victor, «The Lord Treasurer and the Jesuit: Robert Person's Satirical Responsio to the 1591 Proclamation», The Sixteenth Century Journal, 32.2, 2001, pp. 383-401.

Iñurritegui Rodríguez, José María, La Gracia y la República. El lenguaje político de la teología católica y el príncipe cristiano de Pedro de Ribadeneyra, Madrid, UNED, 1998.

Lake, Peter, Bad Queen Bess. Libels, Secret Histories, and the Politics of Publicity in the Reign of Queen Elizabeth I, Oxford, Oxford University Press, 2016. 
Loomie, Albert, Spanish Elizabethans. The English Exiles at the Court of Philip II, Nueva York, Fordham University Press, 1963.

McCoog, Thomas, S.J., The Society of Jesus in Ireland, Scotland and England 1541 1588. «Our way of proceeding»?, Leiden/New York/Koln, Brill, 1996.

Persons, Robert, Elizabethae Angliae reginae Haeresim caluinianam propugnantis saeuissimum in catholicos sui regni edictum quod in alios quoq[ue] Reipub. [...], Augustae, apud loannem Fabrum, 1592.

Persons, Robert, Razonamiento y parecer de dos letrados ingleses sobre el caso de la sucesión del reino de Inglaterra, dividido en dos libros, con un árbol de la decendencia de todos los pretensores de aquel reino desde Gulielmo llamado el Conquistador hasta el día de hoy, que son más de quinientos años, 1594. BNE, Ms. 23.199.

Tanner, Joseph, Tudor Constitutional Documents A.D. 1485-1603, Cambridge, Cambridge University Press, 1951.

Tutino, Stephania, «The Political Thought of Robert Person's Conference in Continental Context», The Historical Journal, 52.1, 2009, pp. 43-62. 